\title{
A Caring Approach to Vocational Education: Supporting Students in Social Work and Nursing Para-Professional Programs in Community Colleges
}

\author{
Tanya Shute ${ }^{1}$, Eva Peisachovich ${ }^{2}$, Celina Da Silva ${ }^{2}$ \\ Laurentian University ${ }^{1}$, York University ${ }^{2}$ \\ Canada
}

\begin{abstract}
Community colleges facilitate the vocational education of students for whom university-level education is not an option. However, significant and concerning numbers of students fail out of their programs for low academic performance, and are left without many options to realize their vocational goals in Ontario and Canada. This paper reflects on academic gatekeeping in nursing and social work para-professional programs in community colleges and critical pedagogy, engaging the work of Paulo Freire to question the social justice values of the service professions in vocational education. A proactive and caring approach to pedagogy is argued to respond to the forces working against critical pedagogy and critical consciousness development in community college para-professional service programs.
\end{abstract}

\section{Introduction}

Program completion rates are a persistent concern for community colleges in Ontario and across Canada. Although Canada has one of the highest degree attainment rates globally, at approximately 35\%, completion for non-university post-secondary education (primarily colleges) is about 26\%. Community colleges in Ontario play an important role in student access to post-secondary education, with $60 \%$ of students entering through its college system [1].

One of the hallmark traits of community colleges is relatively open admissions criteria for students who may not meet the more selective admissions standards of universities. Unfortunately, many Ontario college students voluntarily leave or are involuntarily withdrawn from their professional programs due to poor academic performance [2]. It is generally perceived that completion rates are lower in community colleges because of the practical realities of the students who attend them as their preferred or only option for post-secondary education. In Ontario and Canada, community college students are more likely to be from working-class families, employed full-time, or work more significant numbers of hours than their university counterparts; moreover, these student are more likely to be older and with family caregiving responsibilities or be caregivers to parents, more likely to be the first in their families to attend post-secondary education, and more likely to be less academically prepared due to poor academic performance in secondary school or as a result of vocational streaming practices in secondary schools $[3,4,5,6]$.

The literature on post-secondary student persistence suggests that it is significantly influenced by student characteristics such as age, socio-economic status, and prior academic achievement levels $[7,8]$. For many, access to professional training and designations is made possible by community colleges which has significant implications for access to paraprofessional careers, the primary focus of the vocational program offerings at community colleges. Also, improved equity and human-rights approaches associated with the admissions process and student supports enhance the participation of broader student identities than ever before [9]. This approach is a welcome shift for social justice-based service professions such as social work and nursing, both with dynamic and popular programs in Ontario's community colleges.

\section{Social Work and Nursing Para- Professions in Ontario}

For various valid reasons, some students may want to practice in the health and service professions, such as nursing or social work, but are unable at their unique junctures to undertake the longer time, higher expense, or selective rigour of university programs and therefore pursue para-professional alternatives offered through Ontario colleges. In Ontario, nursing programs are designed to prepare student candidates to become qualified RNs (Registered Nurses), RPNs (Registered Practical Nurses) or NPs (Nurse Practitioners). Since 2015, the College of Nurses of Ontario has required that RNs acquire a baccalaureate 
degree to practice nursing in Ontario. RPNs typically complete a three-year college diploma program. Similarly, as per the Ontario College of Social Workers and Social Services Workers, social workers complete undergraduate and graduate university programs to use the professional title of a social worker. However, the para-professional social work programs, i.e., social services workers or child and youth care workers, attend diploma programs at community colleges. Colleges then serve an important labour force function, expediting the labour force entry of graduates into partial or limited roles of their professions.

\section{Community Colleges and Precarious Students}

Community college students have been referred to as higher education's "third-class citizens" [10]. The students are characterized primarily as under-prepared for the rigours of post-secondary education, even at the community college level. This under-preparation speaks to notions of inadequate secondary school preparation or performance. Still, today's community college student is dizzyingly busy with employment and domestic demands, often seeking the most efficient route to professional jobs. Critical pedagogist, Ira Shor, characterizes two-year career college students as "worker-students,"[10] part of the working class subjected to a distorted form of postsecondary education in preparation for their continued service as working-class labourers. These students are simultaneously working hard at difficult jobs to afford school-related costs while at the same time balancing family and community obligations. The day-to-day realities and obligations of the worker-student interfere with their ability to take on the critical learning process of genuine transformational education, which is sacrificed to the careerism of vocationally focused institutions [10].

Students who take advantage of relatively open admissions criteria at community colleges and find themselves struggling academically are "precarious students" [11]. The students' poor academic performance leaves them in constant danger of failing courses and possibly failing out of their programs but without many other post-secondary options. Some precarious students rely on or choose community college programs either because of the community colleges' relatively open admissions policies and abbreviated, labour market-focused vocational programs that allow students to enter professions at the para-professional levels. Other such students choose these programs because they struggle academically due to their parallel identities and priorities as employees, caregivers, parents; these parallel identities impact these students' vocational and academic goals. Indeed, Grade Point Average (GPA) is a significant predictor of post-secondary persistence, however not necessarily a sound indicator of professional promise. The forces that impact students' perseverance, such as time, finances, and ability to prioritize their academics are perhaps disproportionately unavailable to today's community college worker-students. In general, community college students at the lower end of the higher education hierarchy are characterized as nontraditional post-secondary students, moving through the hurdles of their programs to gain entry to better jobs than their current employment options. Educators and institutions do not typically view them as wellrounded students pursuing the aims of higher education [12].

For professors who take up a critical approach to pedagogy in community colleges, today's students' realities coupled with the low completion rates for these aspiring para-professionals are a unique concern. Critical educators have a social justice responsibility in the classroom to not marginalize or further marginalize precarious students. Indeed, the knowledge and experiences of these students should serve as the foundation for should serve as the foundation for social-justice-based vocational programs such as nursing and social work.

Community college students are community members and, therefore essential voices in the service professions programs. Students in service profession programs at large, urban/metropolitan college institutions are typically students marginalized by their non-traditional post-secondary student identities (i.e., disproportionately racialized, from lower-income households, and often less tenure living in Canada than their university counterparts). These identities contribute to a just and responsive field of social work and nursing professionals, often representing the voices of their families, peers, and communities inside social work spheres, still dominated by traditionally white, cisgender, heterosexual, middle-class identity practitioners. However, it is their community college identities, the profound obstacles they experience in their attempt at vocational preparation, and their marginalized experiences as higher education's "third class citizens", that provides the foundation for genuine ally-ship with our fields' service users, as many could be considered in need of publicly provided health and social services directly or indirectly influenced by socio-economic marginalization.

Retaining the precarious student is not just then an institutional concern as a matter of retention, but also for the lost potential contribution of their knowledge 
and experiences to the field of nursing and social services practice should they be unsuccessful. Their lived knowledge and experiences on the margins are often overlooked or structurally omitted in social work and nursing pedagogy, field work, and professional practice. Therefore, critical vocational educators need to adopt a more proactive caring and critical pedagogy not only to keep precarious students in our classrooms but to ensure that their lived experiences, combined with professional/vocational training, informs their respective fields and maintains the critical social justice lens of their practice and education community.

College professors have further cause for concern for their pedagogical practices in social-justiceoriented para-professional programs like nursing and social services work. Professors are often caught in the professional-pedagogical bind between gatekeeping for their professions and supporting precarious students through the academic journey through to completion and transition into the field. Paulo Freire's approach to critical education is particularly instructive in this regard and is taken up here to argue for a more proactive critical pedagogy in vocational education, one guided by the ethic of caring and commitment to social justice that is inherent to social work and nursing, to address student precarity. González, Moll, \& Amanti's concept of students' funds of knowledge offers some practical insight into offering a more caring approach that could be applied in community college service professional programs.

\section{Gatekeeping in Community College Para-Professional Programs}

Based on a principle of non-exclusion, community colleges were initially envisioned in Ontario as institutions that would accept students prepared by any form of secondary education who were not candidates for university but wanting vocational education and training [12]. Yet, many students are forced out of their programs and these institutions for poor academic performance in practice. Vocational educators perform a gatekeeping role by upholding standards in the credentialing process, a challenging position in failing or dismissing unsuccessful students, but thought to be important in maintaining a profession's rigour [13]. Thus, our commitment to our professions problematically involves gatekeeping and the necessary participation in the dismissal of unsuitable candidates through the training/vocational education process. But we know in that flawed process that we lose students who are badly needed in our fields of practice and as helping professionals in their communities. Educators also must recognize that most students have no control over the structural forces that influence their academic performance (work, family obligations, etc.) but face the consequences of these influences on their GPA individually.

Gatekeeping poses a significant tension for critical vocational educators. Our commitment to supporting students in achieving both a post-secondary education and their vocational goals can be at odds with the understanding the challenges of their non-academic lives and how these challenges distort their academic performance. Indeed, GPA alone is not a genuine indicator of whether or not a student will be an excellent social services worker or practical nurse. For some, educators take the selecting out of "unsuitable" candidates for the profession through academic means - and the rationale here is quite common sense. If a program is well developed to prepare a student for a particular field - in this case nursing or social services - then it seems reasonable to extrapolate that if a student is unsuccessful in those courses or programs, they are either unsuitable for the profession or at least not yet suitable. The educator though, is not one who benignly applies a program of learning and training to individual students for them to demonstrate their preparedness and fit. The quality of our pedagogy and teaching skills and our discretion and subjectivities are involved and therefore, gatekeeping is not a neutral exercise of pedagogy. Professional education is a site of struggle - where the professional is socialized into her profession and where professionals-as-educators construct and reproduce what it is to be a competent professional fit for the field [14].

Professionals-turned-educators bring with them their professional judgment about the competencies needed in ever-changing fields based on their own experiences of the field, and apply them in evaluation. In a transformative gatekeeping turn, it is possible then to select students we think best reflect the qualities and skills that will move these professions forward or the best candidates to realize the social justice goals of our work. This means challenging the convenient gatekeeping logic that poor grades are an indicator of not being fit or ready for professional practice for all students. Requiring that the students demonstrate their professional value academically while their lived knowledge of the margins remains un-integrated and under-valued may not only reflect an outdated way of thinking about gatekeeping but also protect and maintain the social closure of the professions to the margins.

Social work and nursing, both service professions, share similar values and goals from an ethic of caring and social justice. The goals of both approaches allow students to reach their maximum potential and to work with groups, families, and communities to ensure 
equitable access to the tools and resources needed to thrive in their communities according to their own definition. From a social justice orientation, teaching about our service ethic of care means nurturing the skills, values, and attitudes exemplified in our professions. It is highly unlikely that educators employ a similar, proactive, supportive orientation toward our professional-education practice and students experiencing the rigours of post-secondary education practice and contexts. Educators should take a critical view of socializing students to the less caring, less justice-oriented aspects of the profession. It is easy to fall back on tropes of "if you can't make it through the rigours of school, you definitely won't make it in the field" " or ""these are deadline-rich environments, and you won't get flexibility in the real field" or "real -life practice is much more emotionally and physically demanding than just training for it" thus socializing them only to the real, but nonetheless harsher and more neoliberally influenced aspects of our professions, rather than the ethic of caring, compassion, and nonjudgment values of our practices. When students can't "cut it" college educators apply what we conceive of as the standards of our professional fields as they relate to performance in the field: punctuality, attendance, prioritizing. Losing these students through the GPA gatekeeping process then seems only rational. But this process is one of the more domesticating and dehumanizing professional education forces that we must question as critical educators working in professional/vocational programs.

Tension arises when we teach about social justice work and the systems that prevent people from living their lives fully but work in institutional ways that we may disagree with as justice-oriented educators. Simply put, there are things that our professional practice selves do to actively support the autonomy and personal success of the people we serve in professional practice that are not considered within the professional or ethical scope or sanction of the educator to apply to their students. Some examples are listening deeply to their stories of their personal lives and responding in pragmatic ways to difficulties students experience as barriers to their success in their personal lives. We should be focused on socializing them to the caring and inclusive aspects of the professions, not only the harsh deadlines and superhuman workload management they will require. They know those pressures already, toiling under many in their worker-student realities. A more caring vocational pedagogy approach may be a resistance/salve for the neoliberal forces that have so gravely impacted the helping professions. Facilitating worker-students' post-secondary completion and entry into the service fields facilitates humanizing the professional service workforce and facilitating their participation in stable, well-paid, regulated, (however decreasingly so, unionized) jobs.

However, there are legitimate limitations to a more caring pedagogy in the community college-context. Institutional realities of large teaching loads and packed classrooms prevent us from offering a level of individualized support. Professional boundaries are invoked to prevent providing support to students that could be perceived as drifting beyond the teaching relationship and into the professional realm, such as therapeutic counseling. These boundaries are highlighted starkly when we recognize a struggling student but are limited in the ability to respond and engage with them in a way that might reach beyond the classroom and standard interventions of the pedagogical relationship. Teaching about the service professions means nurturing the skills, values, and attitudes as well as the ethic of caring that facilitate the goals of our professions, despite the challenges. Here the work of Paulo Freire offers some guidance.

\section{Freire, Critical Education, and Vocational Education}

Freire's early work was primarily focused on adult literacy education in poor agricultural communities. His critical pedagogy lens was based on the purposive education of adults to enhance their resistance to oppression and exploitation of their labour, but also to resist the oppressive forces of the political act of teaching and learning, which he theorized had the potential to liberate or further the political project of maintaining a disempowered labour class. For Freire, critical pedagogy underscores the need to support students as they gain the social skills necessary to participate in a transformed and inclusive democratic society actively. When people are able to identify the sources of power and can both recognize and understand their position in relation to that power dynamic and its political nature, it empowers and provides them collectively with the tools to seek and develop social action. In the pedagogical process of conscientization, students and their teachers learn to perceive social, economic, and political contradictions and develop critical consciousness, allowing individuals to act against the oppressive social elements that directly impact their daily lives [15]. The daily lives and realities of students become the pedagogical content and focus of transformational education, based on an intimate understanding on behalf of the educator of those very realities.

Critical educators in vocational programs are challenged with aligning themselves with a greater reading of oppression and exploitation in students' 
lives, particularly as they play out in our colleges and our programs themselves, while maintaining our gatekeeping function. However, our argument for a more proactive approach based on the ethic of caring that characterizes service professions is best served by focusing on how Freire learned how to teach for social justice: from his students and their communities. Freire's novice educators would immerse themselves in their students' communities, often living alongside their students and their families, and integrating themselves into the daily life of the community, learning from them first, what is meaningful and important [16]. Educators would then bring these daily realities into the classroom, teaching based on what students knew and lived. Most vocational educators are adept at integrating service user or patients' lived experience into the classroom, but often miss the opportunity to do so with their students' lives, families, and communities.

The argument for a more critical caring approach to nursing and social-work education, particularly in the community college context, is necessary to genuinely engage students in the helping service relationship and socialize them to the social justice elements of the health care practice domain to foster as practitioners-turned-educators. Students in community colleges, worker-students attempting to earn a credential not only at the lower rungs of the professional hierarchy, have enough experiences of barriers, hurdles, deadlines, expectations to prepare them for the professional practice field. The current community college worker-student reality is that most students cannot make their studies their first priority, as competing time priorities (parenting, employment, transnational ties and obligations, well-being) may not leave students with the 40,50 , or $60+$ hours required weekly for successful post-secondary/vocational training. They may not have enough of care and compassion from people at the gates, the values and principles of our professions, and this is what we educators ultimately would want future practitioners to embody in our fields that we do diligently protect and uphold. A greater focus on critical consciousness in vocational programs, combined with a more caring approach to critical pedagogy would not only improve retention but perhaps resolve gatekeeping tensions educators experience in these programs.

\subsection{Critical Consciousness and Vocational Education}

Freire questioned professionalized higher education in terms of its potential to foster critical thinking, noting that it contributes to a narrow focus merely on professional specialization and not to a greater reading of the world. Para-professional programs are shorter in duration than their professional program counterparts in universities (diplomas versus degrees), and as such, are more focused on the essential preparation for practice in these highly complex professions. A restrictive curriculum, though, undermines a program's socialjustice potential [17], and arguably, the profession's social-justice potential by extension. For example, a restrictive curriculum does not afford the time for students to learn about and debate different positions and theories, explore the evidence-base of practice of interventions for themselves, or take time to specialize their knowledge. Educators are forced to focus only on the bare minimum necessary, teaching to the entry-topractice competencies deemed required, and providing fewer and fewer opportunities for the dialogue or academic discourse necessary to foster critical consciousness [18]. Large classes and low full-time faculty-to-student ratios, the reliance on part-time faculty who are often juggling multiple jobs, the emergence and popularity of micro-credentials and quick/fast-track programs in which students may be in abbreviated programs for only a few semesters before graduating, all contribute to a restricted curriculum on just what is necessary for professional preparation.

The narrow training focus of professional programs has the dangerous potential to turn underprepared students into underprepared workers, who lack the depth and breadth of preparation needed for the growing complexities of the health and social services field and the critical knowledge necessary to question forces such as neoliberalism, rampantly evident in the health and social service sector in which they aim to practice. Critical thinking and reasoning are at the root of service professions, particularly nursing and social work practice, as sites of service that can involve significant professional judgment and discretion, and also has a material redistributive function of limited public resources (e.g., health care access or social assistance).

To complicate matters, adult education principles dominate post-secondary education, wherein students are expected to take on independent and autonomous responsibility for their trajectories through postsecondary education, managing their family and employment roles and obligations in separate compartments. As such, educators cannot practically come to know students' worlds; their families, communities, or stories, under these conditions. A more proactive caring critical pedagogical approach is transformative not only of the vocational education experience but also of the professional gatekeeping practices that become justified under these limiting conditions. 
Educators must find ways to introduce transformative and liberatory possibilities inside of this vocational education realm. By helping students who are considered non-traditional or precarious gain entrance to the service fields ensures they participate in their communities in leadership and service roles, educators can at the very least contribute to social change outside the compressed classroom experience. Perhaps the real value of para-professionals, in terms of social justice values, can be found in who the paraprofessionals are and in the contributions they make when they are successful in their programs and enter the field, as "in many organizations, non-degreed workers [para-professionals] provide many direct services and represent community voices" [19]. More importantly, their lived knowledge and experiences of caregiving, meeting multiple demands, and striving for well-being and goal attainment despite significant challenges represents an opportunity for transforming the health and social services field and maintaining its social justice promise.

\section{Proactive Caring Approach to Critical Vocational Pedagogy}

Reflecting Freire's critical pedagogy, a proactive caring critical vocational pedagogy recognizes and integrates students' everyday lives and communities in two ways: 1) as the context for conscientization work in the classrooms and also 2) the context for supporting students through the vocational training encounters to facilitate their entrance in the field, not only to socialize them to practice but also building conscientization about what that practice should look like from a social justice orientation.

It is possible to make a proactive, caring effort to learn a greater reading of worker-students' worlds and everyday lives, especially what makes community college students unique in the post-secondary hierarchy of students: their work, their caring obligations, their financial responsibilities and pressures, their strengths for managing these demands, their family and community resources, priorities, and methods for addressing concerns. This concept calls for a reorienting of the assumed priorities and resources of the student. The classroom is just another part of their busy lives, and not necessarily the most important or the most significant part. Students' daily lives, including their college experiences, may often exemplify the community knowledge that aptly prepare students for critical professional nursing and social work approaches.

Critical educators must work at the level of institutional transformation, resisting pressures from the institution to dismiss students who interfere with completion-performance statistics and adhere to standard timelines implementation and academic practices like penalties for not attending classes regularly. Educators in the community college context must consider processes such as requiring students to establish their eligibility for academic accommodations, a process that closely resembles the professional eligibility gatekeeping roles that frustrate professionals and cause gaps in important services for our clients. Or re-consider our rules for classroom behaviour: no lateness, no children, no eating, no cellphones - all of which are opportunities for students to juggle their personal and community lives, and opportunities for educators to bring them into the classroom. Adhering to our institutional and "professional behaviour" demands on educators do not reflect an understanding of the complexities of some students' lives and their pathways through postsecondary education but instead are "the way things are done here," investing in the trope that the application of these practices reflects the rigours and demands of the professional fields for which we are preparing them for, or following the policies and procedures of the institution unquestioned. These are not neutral practices; the exercise of discretion over these success/failure policies and practices, as Freire reminds us, has a political dimension. This approach is more than "student-centered" in terms of thinking about the needs and barriers for students in our judicious approach to our pedagogy, but rather about making visible the problematic technologies we employ in service of professional gatekeeping - who gets in, and who is kept out and based on criteria that reflects what it means to be "a professional". This transformation must be done not from a perspective of creating conditions for "success" (read, as passing courses); rather, it should reflect a serious commitment to the students themselves, who are about to engage explicitly in the vocational preparation process that has the critical potential to prepare them to intervene in the world of others in a liberatory and transformational manner.

A proactive caring critical pedagogy approach to teaching is more in line with the philosophical orientations for both nursing and social work and their code of ethics and conduct, which guide vocational education in the disciplines. Nursing and social work are situated in caring philosophical practice. Further, the practice and pedagogy of both disciplines is strongly focused on the primacy and meaningfulness of personal narratives, lived experience, and clarifying beliefs and values. Learning occurs in relational contexts that consist of interactions between student and student, teacher and student, service user/patient and student; and practitioner and student. Both nursing 
and social work's approach to liberation/transformation is through a caring lens, stemming from a perspective of shared professional ambition of collective health, wellness, and quality of life for all. Professional and pedagogical knowledge is further developed beyond the technical aspects of the professions by understanding lived experience and its complexities. However, nursing and social work as professions have their challenges in the ethic of caring context, having some troubling aspects to confront.

The field of nursing has been at times a place of professional bullying and intimidation, and this sometimes infects nursing education as well [20]. Racism, homophobia/transphobia, ableism among health care providers in general is becoming more recognized, and hostility and mistrust within the profession is due in part to learned oppressive behaviour transmitted in nursing programs. These behaviours may significantly impact our ability to promote and empower humanization in and of nursing education.

Social work's tradition of working toward social change and an ethic of caring is encoded in its various professional documents, including codes of ethics, mission and values statements, and standards of practice. Established therein are concerns for humanity, human rights, self-determination, corresponding values and principles, and a call to work toward individual well-being and social transformation. However, social work is not all benevolence, having been instrumental in the child removal practices of the $60 \mathrm{~s}$ scoop and ongoing removal of Indigenous children from their homes and families, as one example of our troubled practice.

Vocational educators in the helping professions must also engage in conscientization about the oppressive factors of our professions, mentoring students to foster their critical thinking skills about the profession they are about to enter into and how they will shape their practice. Many students themselves will have had direct experience of health and social services encounters, and their lived experience has significant pedagogical promise for the conscientization of both fellow students and educators. Many of their family and community members may have shared experiences of the negative or oppressive encounters with these professions and are in a unique position to transform future practice.

\subsection{Students' Families in a Caring Critical Vocational Pedagogy}

Students who fail out of their college programs often do not access institutional supports until it is too late or at all, despite our default expectation as faculty that they should and will do so in order to prevent their own failing out of college. When institutional supports are ineffective or avoided, families provide both a buffering and exacerbating influence on struggling students. They provide the strength, support, and motivation to persist, but also represent responsibilities and obligations that take priority over studies and attendance, especially for students who are parents and caregivers. This is especially true for community college students, who are more likely to be responsible for dependents or be single parents than their university counterparts.

Practicing the Freirean pedagogy principle of immersion in the knowledge of our students' communities is difficult in the community college context. Rarely do educators live in the same communities as their students given the broad geographical jurisdiction of large community colleges, especially now with the trend to increasing international students and online opportunities where students could be halfway around the world in our virtual classrooms. Therefore, a critical caring approach calls for educators to bring families and community into pedagogy and the classroom and to engage reciprocally with these critical determinants of the student experience. Focused on caring pedagogy to support young students considered at-risk, the funds of knowledge [21] pedagogical approach is valuable. As a community-based pedagogy, the funds of knowledge approach means that reflective educators engage in reciprocal relations with student families and households in the pedagogical project. The ability to engage students' families is limited in an adult education context in colleges or university settings; educators draw a line when communicating with family members. Many community college students are primarily unable to remove an arbitrary line between their student life and their real life. Therefore, if we could invite students' lives in, we might address some significant dimensions of student retention and with the added benefit of contributing to their family and community wellbeing on practical levels as well as merely demonstrating a caring attitude toward them and their journeys.

A community-engaged pedagogy and professional program - which nursing and social services worker programs should be-would, by proxy, necessarily bring families, communities, and daily life into the classroom. Students would thereby experience less of a divide between their academic and community lives, and community funds of knowledge would enrich classrooms. Prioritizing student and community funds of knowledge requires a reordering of students' assumed priorities and resources so that the classroom is just another part of their social network [21], rather 
than the most important or consequential part of their lives. For many of the students, their post-secondary experience is a source of burden or obligation-one that had to be dealt with as minimally or as efficiently as possible. It does not typically enhance their quality of life or what they were experiencing at the moment, nor does it offer them solutions to their life challenges. Educators expect students to prioritize and sacrifice for their future gain, perhaps because as students that's what we were able to do but also because we believe the high standards of our professions require sacrifice. Still, perhaps this orientation speaks to a framework or context no longer relevant for worker-students or academically precarious students. The old way of thinking posited that persistence was enhanced the more the student integrated into academic culture/community, but ignored that doing so came at a cost to the students' communities and families (e.g., This way of thinking is exemplified by Tinto's early departure theory) [22]. Taken together, the conditions of professional/vocational education and the implications for its students and faculty prevent us from engaging in meaningful relationships with our mass student population, let alone with their families and communities - the critical aspects of our students' daily lives that they bring with them to every class. In terms of critical pedagogy, students' and instructors' daily struggles and lived realities are a meaningful starting point for critical-consciousness development in the classroom [23]. Students' lives and experiences, especially their experiences of nursing and social services, as funds of vocational knowledge, are especially relevant to critical-orientation professions/para-professions, given that many precarious students have direct experiences of marginalization and of systems of bias and oppression; in the classroom, these experiences can help to make the connections between the oppressive systems and institutions that impose limitations and barriers on marginalized groups. Providing students with the opportunity to critically reflect on the everyday, routine systems and social relations of their lives and the freedom to take the time necessary for this reflection is our responsibility as social-justice educators, because the daily college encounter may be the only space left in their busy lives to do so. This opportunity provides the space for students to separate temporarily from aspects of their daily lives and render them up for view and reflection to unpack that reality develop critical consciousness about their workerstudent lives (if needed) or engage their critical consciousness about their own contexts as a powerful fund of knowledge for the learning of others, including the instructors, and consider implications for practice.
Students' daily lives are rich sources of helping and caregiving, which is especially relevant to the nursing and social work field. Although some students describe their obligations to families as a reason for struggling with the obligations of academic life, in terms of household and family functioning or wellbeing, as well as in terms helping and supporting, these students are rich. Instead of identifying these issues as burdens or deficits (because they interfere with the ability to attend class, focus, or do the work), we could strategically engage the complexity of the realistic portrait of post-secondary student workers, caregivers, and community members in the classroom and training project, thus debunking their academic "unpreparedness." We should be finding ways to integrate their families and communities; caregiving priorities should be viewed as part of students' knowledge and experience and thus as a means for creating meaningful connection that allows students to cope with their burdens and obligations without severing them from their academic lives. This may be as simple as a gesture of caring and kindness that students may have come to not expect from their college encounters. Students could, for example, be allowed to bring children into classroom spaces when childcare falls through at the last minute, which, as a general rule, is not allowed in either nursing or social-services programs due to institutional liability concerns and the practical matter of distraction in class. College instructors are very used to distracted students and to incorporating spontaneous occurrences into learning opportunities in class. It is in these moments that educators can choose to respond as an agent of the institution or as a transformative agent of critical pedagogy, thereby creating a possibility for bringing life and community into the classroom as a practical means to support "distracted" students and to engage what students already know in the project of conscientization of nursing and social work professionals.

Critical pedagogy needs to value and embrace a reciprocity between our professional selves, the pedagogical relationship, and the everyday lives of our students. Here González, Moll, and Amanti (2005) offer a practical means for providing the opportunity for reciprocal relationships of teaching and learning that are advocated by Freire and by critical pedagogy. González et al.'s [23] networks of exchange involve bringing students' funds of knowledge from their homes and personal lives and experiences into the classroom, yet this begs the question what is reciprocated? Adapting a funds-of-knowledge approach requires that educators actively engage, as learners involved in a reciprocity and network of exchange, with student households. For example, 
educators can integrate reciprocity into their pedagogy, offering and exemplifying service roles such as language translation, helping to fill out forms, providing referral and advice regarding community resources they were knowledgeable about because of our roles as educators and enhanced by our service practitioner backgrounds. This would be a real departure from our current pedagogical orientation, but in terms of relationship-building, providing some level of practical support (within the limits of our professional standards) may be more consistent with our orientation as service professionals and our values and principles than passively waiting for the students to interact with us.

Integrating students' realities (their responsibilities and obligations), which educators often or easily construct as distractions from their academic and social adjustment to post-secondary demands, is crucial, and requires a paradigm shift in vocational pedagogy. It is mandatory that we integrate these daily realities - these funds of knowledge - into formal study, not merely to retain students, but because failure to do so precipitates an alienating and dehumanizing process that focuses solely on "domesticating them in the methods of the discipline" [24].

\section{Conclusion}

The consequences of precarious worker-students failing out or quitting professional programs include the student's removal from an environment where so much growth and opportunity is supposed to be readily available. Not that they would not find this arena or opportunity otherwise, but here is at least one opportunity to understand that systemic and social conditions are changeable and, in their power and that of others to transform in their future professional practice as service providers. Given these professions' relation to social justice practice, our classrooms offer a fertile ground for resisting the usual tropes of vocational education in community colleges.

Nursing and social work should be conceived of as activist endeavours, not merely professional ones. Students could thus be supported to engage and participate more fully by integrating their daily lives, their families, and their struggles directly in a relationship of reciprocity, as advocated by the funds of knowledge approach. To engage in the usual tropes of vocational education gatekeeping: you've got to be able to 'cut it' in college, before you get out into the 'real world", when most of these students' real worlds reflect the realities of those they will serve as professionals, is to engage in a dehumanizing process for the educational actor, and this reflects poorly on our professional values, principles, and commitments. A proactive, caring critical pedagogy approach to vocational community college service programs serves our professional goals and values better, and offers a chance for knowledge from the social margins to be better represented in our professions.

The material conditions of students' livesincluding, but not limited to, family structures, financial struggle or insecurity, and mental health challenges - are significant indicators of how they will perform at the academic level, which critical pedagogy will not change alone. Although critical pedagogy can expose the injustices in these students' lives and the wider academic community, this poses many implications for praxis.

As critical educators in service professions, we must consider the complexities of students' lived experiences and advocate for more inclusive socially and politically engaged academic milieus and curricula. This may involve working with professional associations and labour unions to collaboratively engage in social movements to build equitable communities of practice and defend para-professional education. As educators immersed in caring and service professions, we need to standardize a strong sense of community activism to facilitate a context that alleviates both the extent to which students are marginalized by social identity and para-professional education status and the extent to which they experience our institutions, classrooms, and pedagogy as dehumanizing.

\section{Implications for Praxis}

In employing a more proactive caring approach to critical pedagogy in vocational education, it is essential to employ a gendered analysis of caregiving and emotional labour in this context. As nursing and social work professions and its vocational education sites are female-dominated, it is crucial that a more caring approach is not read as adding to women's emotional labour and invisible care work in the academy or burden them with greater responsibility for providing supportive pedagogical responses. A proactive caring critical approach is about bringing all of the student into the vocational encounter, while at the same time demonstrating a similar approach to the academic work of our colleagues. BIPOC (Black, Indigenous, and People of Colour) faculty and LGBTQ+ (Lesbian, Gay, Bisexual, Transgender, Queer and others who do not conform to dominant heterosexual and gender binaries) faculty do disproportionately more unrecognized emotional labour in supporting fellow BIPOC and LGBTQ+ students in our programs. Caring and critical education 
extends our lens to our fellow faculty as well, for the funds of knowledge they bring to their pedagogy that is also largely unrecognized.

\section{References}

[1] Skolnik, M.L. Ontario Colleges in Comparative Perspective, Centre for the Study of Canadian and International Higher Education, OISE University, Toronto, 2020 .

[2] Lopes-Rabson, T.S., and McCloy, U., Understanding Student Attrition in the Six Greater Toronto Area (GTA) Colleges. Higher Education Quality Council of Ontario, Toronto, Ontario, 2013.

[3] Daiek, D., Dixon, S., and Talbert, L. (2012) "At Issue: Developmental Education and the Success of Our Community College Students", Community College Enterprise, 18(1), pp. 37-40.

[4] Daley, F. (2010) "Why College Students Drop-out and What We Can Do about It", The College Quarterly, 13(3), pp. 1-5, http://collegequarterly.ca/2010-vol13-num03summer/daley.html (Access Date: 17 May 2021).

[5] Frenette, M. (2008) "Why are lower-income students less likely to attend university? Evidence from academic abilities, parental influences, and financial constraints", in Who Goes? Who Stays? What Matters? Accessing and Persisting in Post-Secondary Education in Canada (R. Finnie, R.E. Sweetman, and A. Usher, Editors), McGillQueen's University Press, Montreal and Kingston, pp. 279298.

[6] Harbour, C.P. and Ebie, G. (2011) "Deweyan Democratic Learning Communities and Student Marginalization", New Directions for Community Colleges, 155, pp. 5-14. Doi:10.1002/cc.453

[7] Mueller, R.E. (2008) “Access and persistence of students in Canadian post-secondary education: What we know, what we don't know, and why it matters", in Who Goes? Who Stays? What Matters? Accessing and Persisting in PostSecondary Education in Canada (R. Finnie, R.E. Sweetman, and A. Usher, Editors), McGill-Queen's University Press, Montreal and Kingston, pp. 33-62.

[8] Vaccaro, A. (2012) "An Analysis of Access Barriers to Post-Secondary Education”, College Quarterly, 15(4), pp.112. http://collegequarterly.ca/2012-vol15-num04-fall/vacca ro.html (Access Date: 17 May 2021).

[9] Finnie, R., Sweetman, R.E., and Usher, A. (2008) Who Goes? Who Stays? What Matters? Accessing and Persisting in Post-Secondary Education in Canada, McGill-Queen's University Press, Montreal and Kingston.

[10] Shor, I. (1987) Critical Teaching and Everyday Life, The University of Chicago Press, Chicago, Illinois.
[11] Shute, T. (2018) Disinvited Students: Social Work, Community Colleges, and the Process of Mandatory Withdrawal (Doctoral dissertation). Retrieved from: https://yorkspace.library.yorku.ca/xmlui/handle/10315/ 35579 (Access Date: 21 April 2019).

[12] McEldowney Jensen, J., and Worth, B. (2014) "Valuable Knowledge: Students as Consumers of Critical Thinking in the Community College Classroom", The Journal of General Education, 63(4), pp. 287-308. Doi: 10.1353 /jge.2014.0025

[13] Grady, M.D. (2009) "Gatekeeping: Perspectives from Both Sides of the Fence", Smith College Studies in Social Work, 79, pp. 51-64. doi: 10.1080/ 00377310802634616

[14] Ford, P. and Hayes, T. (1996) Educating for Social Work: Arguments for Optimism, Avebury, London, UK.

[15] Freire, P. (1970, 2007) Pedagogy of the Oppressed, continuum, New York, New York.

[16] Freire, P. (1998, 2005) Teachers as Cultural Workers: Letters to Those who Dare to Teach, Westview Press, Cambridge, Massachusetts.

[17] Crabtree, S.A., Hussain, F., and Spalek, B. (2017) Islam and Social Work: Culturally Sensitive Practice in a Diverse World (2nd ed.), Policy Press, Bristol, England.

[18] Bizzell, P. (1992) Academic Discourse and Critical Consciousness, University of Pittsburgh Press, Pittsburgh, Pennsylvania.

[19] Gibelman, M. and Furman, R. (2008) Navigating Human Services Organizations (2nd ed.), Lyceum, Chicago, Illinois.

[20] Clarke, C.M., Kane, D.J., Rajacich, D.L., and Lafreniere, K. (2013) "Bullying in Undergraduate Clinical Nursing Education”, Journal of Nursing Education, 51(5), pp.269-276. Doi: 10.3928/01484834-20120409-01

[21] González, N., Moll, L., and Amanti, C. (2005). Funds of Knowledge: Theorizing Practices in Households, Communities, and Classrooms, Routledge, Milton Park, UK.

[22] Tinto, V. (1993) Leaving College: Rethinking the Causes and Cures of Student Attrition, University of Chicago Press, Chicago, Illinois.

[23] González, N., Moll, L., and Amanti, C. (2005). Funds of Knowledge: Theorizing Practices in Households, Communities, and Classrooms, Routledge, Milton Park, UK.

[24] Shor, I. (1987) Critical Teaching and Everyday Life, The University of Chicago Press, Chicago, Illinois. 